\section{Perancangan Belt Conveyor sebagai Alat Material Handling pada Terminal Peti Kemas Surabaya}

\author{
Annisa Kesy Garside ${ }^{1}$ Fitra Risaldi ${ }^{1}$ Shanty Kusuma \\ Dewi $^{1}$ \\ 1Program Studi Teknik Industri, Universitas \\ Muhammadiyah Malang
}

annisa_garside@yahoo.com
Proses penanganan material merupakan kegiatan utama yang dilakukan pada PT. Pelabuhan Indonesia III dimana perusahaan bergerak dalam bidang jasa kepelabuhan. Namun kenyataannya, proses penanganan material di departemen pergudangan Terminal Peti Kemas masih kurang efisien. Hal ini disebabkan bongkar muat cargo bag dengan menggunakan forklift memerlukan kurang lebih 10 buruh untuk mengangkut 8o-85 ton per jam. Buruh angkut harus memindahkan material berupa cargo bag dari tumpukan ke pallet, kemudian material diangkut menggunakan forklift ke truk muatan untuk dibawa ke area muat dek kapal. Pada kondisi ini terdapat beberapa kekurangan, waktu yang terbuang saat buruh idle, biaya pallet, dan biaya lembur jika perusahaan menggunakan buruh yang sama lebih dari satu shift kerja dalam satu hari. Tujuan penelitian ini adalah mengusulkan alat material handling yang mampu meningkatkan kapasitas bongkar muat perusahaan. Alat ini berupa belt conveyor yang akan digunakan untuk memindahkan cargo bag dari tumpukan ke truk tanpa harus melakukan penyusunan ke pallet. Perancangan belt conveyor didasari oleh perpektif pengguna dan perhitungan kapasitas belt conveyor, dengan perancangan ini proses yang dilakukan menjadi lebih singkat serta kapasitas bongkar muat meningkat sebesar $87,5 \%$ dari kapasitas sebesar 80 tph menjadi 150 tph.

Kata kunci: material handling, bongkar muat, peti kemas, conveyor

Diajukan: 13 September 2019

Direvisi: 14 September 2019

Diterima: 2 Oktober 2019

Dipublikasikan online: 3 Oktober 2019

\section{Pendahuluan}

PT. Pelabuhan Indonesia III atau disingkat Pelindo III adalah Badan Usaha Milik Negara (BUMN) yang bergerak di bidang jasa kepelabuhan dan berkantor pusat di Surabaya, Jawa Timur. PT. Pelindo III mengelola 43 pelabuhan yang tersebar di 7 provinsi seluruh Indonesia dan menjalankan bisnis inti sebagai penyedia fasilitas jasa kepelabuhan. Proses penanganan material merupakan kegiatan utama yang dilakukan pada Pelindo III. Namun kenyataannya, proses penanganan material di departemen pergudangan Terminal Peti Kemas masih kurang efisien. Hal ini disebabkan bongkar muat cargo bag dengan menggunakan forklift memerlukan kurang lebih 10 buruh untuk mengangkut 80-85 ton per jam. Buruh angkut harus memindahkan material berupa cargo bag dari tumpukan ke pallet, kemudian material diangkut menggunakan forklift ke truk muatan untuk dibawa ke area muat dek kapal.

Proses bongkar muat dengan forklift menjadi cukup lama karena harus menyusun cargo bag diatas pallet terlebih dahulu, sehingga perusahaan sering kali lembur agar dapat memenuhi permintaan proses penanganan komoditas barang. Hal ini merupakan pemborosan karena perusahaan harus membayar upah yang lebih tinggi dengan lembur tersebut. Selain itu perusahaan juga mengeluarkan biaya untuk pallet. Oleh karena itu diperlukan rancangan material handling equipment (MHE) yang efektif dan efisien agar perusahaan dapat meningkatkan produktivitas dalam aktivitas penanganan materialnya.

Salah satu jenis alat pengangkut yang sering digunakan oleh kebanyakan industri adalah belt conveyor yang berfungsi memindahkan bahan-bahan berbentuk padat (Aosoby dkk., 2016). Belt conveyor memiliki kapasitas angkut yang cukup besar (500 sampai $5000 \mathrm{~m}^{3} / \mathrm{jam}$ atau lebih), pemindahan barang dapat dilakukan secara kontinyu, jarak pemindahan yang cukup jauh (500-1000 $\mathrm{m}$ atau lebih), lintasan tetap serta bahan material yang dapat diangkut dapat berupa muatan curah (bulk load) atau muatan satuan (unit load), berat mesin relatif ringan serta pemeliharaan dan operasional yang mudah (Zainuri, 2012). Kemampuan ini telah menjadikan belt conveyor secara luas digunakan sebagai mesin pemindah bahan (Raharjo,

Cara mensitasi artikel ini:

Garside, A. K., Risaldi, F., Dewi, S. K (2019) Perancangan Belt Conveyor sebagai Alat Material Handling pada Terminal Peti Kemas Surabaya. Buletin Profesi Insinyur 2(2) 069-075 
2013). Penelitian ini bertujuan mengusulkan rancangan MHE berupa belt conveyor agar perusahaan dapat meningkatkan kapasitas proses bongkar muat sehingga biaya lembur buruh dapat ditekan seminimal mungkin.

\section{Metode}

Identifikasi kebutuhan pelanggan merupakan langkah pertama dalam konsep perancangan produk. Untuk mengetahui kebutuhan tersebut maka dilakukan proses wawancara dan penyebaran kuesioner. Wawancara kepada supervisor, foreman, dan buruh angkut pelabuhan, sebagai pihak yang dianggap berkaitan langsung dalam perancangan MHE. Penyebaran kuesioner dilakukan untuk mendapatkan data tentang keinginan pelanggan dan persepsi kebutuhan ideal yang diperlukan untuk menetapkan ide rancangan pada spesifikasi akhir produk. Langkah kedua adalah intepretasi data kebutuhan pelanggan yang merupakan jawaban dari identifikasi kebutuhan pelanggan. Intepretasi kebutuhan pelanggan menuntun dalam menetapkan spesifikasi produk, membuat konsep produk dan menyeleksi konsep. Langkah ketiga adalah menetapkan target spesifikasi produk. Proses penetapan spesifikasi terdiri dari empat langkah yaitu: menyiapkan gambar metrik, mengumpulkan informasi tentang pesaing, menetapkan nilai target ideal dan marginal yang dapat dicapai untuk tiap metrik, dan merefleksikan hasil dan proses (Ulrich dan Eppinger, 2011).

Langkah keempat adalah membuat konsep produk. Konsep produk merupakan gambaran singkat bagaimana produk memuaskan kebutuhan pelanggan. Proses penyusunan konsep produk terdiri dari empat langkah, yaitu: mengembangkan model-model teknis suatu produk; mengembangkan model biaya dari sebuah produk; memperbaiki spesifikasi, melakukan trade off jika diperlukan; menurunkan spesifikasi menjadi spesifikasi sub-sistem jika diperlukan. Langkah kelima adalah pemilihan konsep desain. Pada tahap ini, akan dilakukan penyaringan dan penilaian untuk mendapatkan konsep desain final. Langkah terakhir yang dilakukan oleh tim pengembang yang terdiri dari pembuatan sketsa dalam bentuk CAD untuk mendapatkan gambaran secara jelas tentang spesifikasi akhir dari hasil rancangan produk. Selanjutnya dilakukan analisis untuk mengetahui peningkatan produktivitas yang didapat setelah dilakukan perancangan.

\section{Hasil Kerja}

Pada kondisi eksisting, proses bongkar muat pada departemen pergudangan Terminal Peti Kemas Surabaya menggunakan material handling equipment berupa Forklift dengan kapasitas 80 ton per hour (tph). Sedangkan spesifikasi material yang akan diangkut adalah cargo bag dengan massa jenis maksimal $180 \mathrm{Kg} / \mathrm{m}^{3}$ dan lebar maksimal $80 \mathrm{~cm}$. Batasan awal rancangan merupakan spesifikasi awal dari hasil rancangan yang akan didapat yaitu adalah: kapasitas yang diinginkan sebesar 150 ton per hour (tph), lokasi outdoor, dan jarak yang diperlukan $16 \mathrm{~m}$.

\section{Identifikasi kebutuhan user}

Jumlah sampel yang akan diwawancarai diperoleh menggunakan rumus Slovin. Dengan jumlah populasi sebanyak 55 dan peluang kesalahan $10 \%$ diperoleh jumlah sampel $35,4 \approx 36$ orang. Komposisi sampel diambil dari pekerja dalam satu shift yang terdiri dari 1 orang supervisor, 1 orang foreman, dan 34 buruh angkut. Peneliti melakukan wawancara untuk identifikasi kebutuhan user dengan memberikan pernyataan mengenai fungsi, keunggulan, kelemahan, dan usulan perbaikan yang diinginkan user.

\section{Interpretasi kebutuhan user}

Pada langkah ini dilakukan pengelompokan setiap kebutuhan menjadi sebuah hierarki. Hierarki yang didapat berdasarkan pernyataan kebutuhan user dimana jika semakin sering sebuah pernyataan disebutkan maka hierarki dianggap semakin penting yang dijelaskan dengan jumlah tanda $\left({ }^{*}\right)$ yang dilakukan oleh peneliti serta supervisor perusahaan sebagai pelanggan pada perancangan MHE ini. Setelah mengelompokkan kebutuhan menjadi daftar hierarki maka tim pengembang membuat prioritas pilihan dan mengalokasikan sumber daya dalam mendesain produk. Tabel 1 menunjukkan derajat kepentingan yang diperoleh dari hasil wawancara dimana 5 menyatakan sangat penting dan 1 menyatakan sangat tidak penting.

\begin{tabular}{|c|c|c|}
\hline No & Kebutuhan & Kepentingan \\
\hline 1. & $\begin{array}{l}\text { Belt conveyor digunakan untuk mengangkut } \\
\text { material dari tumpukan gudang ke truk } \\
\text { muatan }\end{array}$ & 5 \\
\hline 2. & Dirancang semi-otomatis & 4 \\
\hline 3. & Awet digunakan & 5 \\
\hline 4. & Mudah dalam perawatannya & 3 \\
\hline 5. & Mampu meningkatkan produktivitas & 3 \\
\hline 6. & Desain modern & 1 \\
\hline 7. & Desain fleksible & 3 \\
\hline 8. & Material tidak mudah tercecer & 4 \\
\hline 9. & Tidak bising saat beroperasi & 2 \\
\hline 10. & Tidak memakan banyak area & 3 \\
\hline 11. & Tidak polutan & 2 \\
\hline 12. & $\begin{array}{l}\text { Terbuat dari bahan yang tahan banting } \\
\text { tekanan }\end{array}$ & 3 \\
\hline
\end{tabular}

\section{Penetapan spesifikasi produk}

Dalam menetapkan spesifikasi produk dimulai dengan menentukan metrik sebagai jawaban dari kebutuhan pekerja. Gambar 1 menunjukkan metrik panjang belt conveyor sampai $16 \mathrm{~m}$ adalah jawaban dari kebutuhan belt conveyor digunakan untuk mengangkut material dari tumpukan gudang ke truk muatan. 


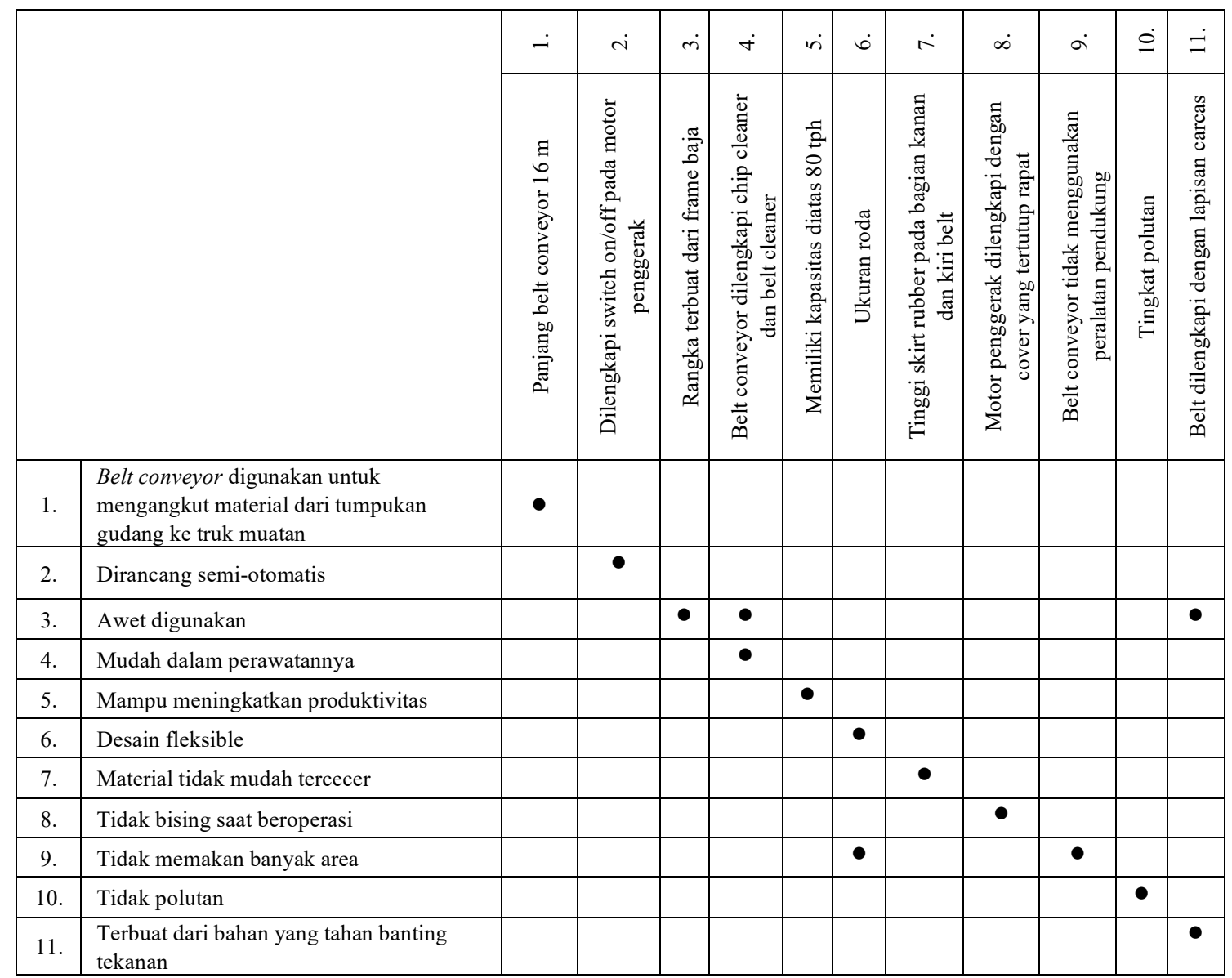

Gambar 1 Metrik kebutuhan pelanggan

Metrik Belt conveyor dilengkapi dengan switch yang built-in pada motor penggerak adalah jawaban untuk kebutuhan pekerja untuk MHE dirancang semiotomatis, dan seterusnya. Selanjutnya, peneliti mengumpulkan dan menganalisis produk pesaing. Informasi belt conveyor pesaing yang dikumpulkan adalah merk Ammeraal Beltech dan Chiorino. Kedua merk ini dipilih karena merupakan dua merk yang merepresentasikan merk superior (Ammeraal beltech) dan inferior (Chiorino). Langkah terakhir adalah memberikan nilai marginal dan ideal pada setiap metrik kebutuhan yang akan menjadi dasar spesifikasi rancangan. Tabel 2 menunjukkan spesifikasi target belt conveyor.

\section{Perhitungan produktivitas belt conveyor}

Perhitungan produktivitas belt conveyor dilakukan untuk mendapatkan spesifikasi teknis dalam meningkatkan produktivitas proses bongkar muat perusahaan yang saat ini sebesar 80 tph.
Tabel 2 Pengukuran derajat kepentingan

\begin{tabular}{|c|c|c|c|c|}
\hline No & Kebutuhan & Metrik & $\begin{array}{c}\text { Nilai } \\
\text { marginal }\end{array}$ & $\begin{array}{l}\text { Nilai } \\
\text { ideal }\end{array}$ \\
\hline 1 & 1 & $\begin{array}{l}\text { Panjang belt conveyor } \\
16 \mathrm{~m}\end{array}$ & & 16 \\
\hline 2 & 2 & $\begin{array}{l}\text { Dilengkapi switch } \\
\text { on/off pada motor } \\
\text { penggerak }\end{array}$ & & $\mathrm{Ya}$ \\
\hline 3 & 3 & $\begin{array}{l}\text { Rangka terbuat dari } \\
\text { frame baja }\end{array}$ & & $\mathrm{Ya}$ \\
\hline 4 & 3,4 & $\begin{array}{l}\text { Belt conveyor } \\
\text { dilengkapi chip cleaner } \\
\text { dan belt cleaner }\end{array}$ & & $\mathrm{Ya}$ \\
\hline 5 & 5 & $\begin{array}{l}\text { Memiliki kapasitas } \\
\text { diatas } 80 \text { tph }\end{array}$ & 80 & $>80$ \\
\hline 6 & 6,9 & Ukuran roda & $150-200$ & 200 \\
\hline 7 & 7 & $\begin{array}{l}\text { Tinggi skirt rubber } \\
\text { pada bagian kanan dan } \\
\text { kiri belt }\end{array}$ & 200 & 250 \\
\hline 8 & 8 & $\begin{array}{l}\text { Motor penggerak } \\
\text { dilengkapi dengan } \\
\text { cover yang tertutup } \\
\text { rapat }\end{array}$ & & $\mathrm{Ya}$ \\
\hline 9 & 9 & $\begin{array}{l}\text { Belt conveyor tidak } \\
\text { menggunakan } \\
\text { peralatan pendukung }\end{array}$ & Ya & $\mathrm{Ya}$ \\
\hline 10 & 10 & Tingkat polutan & 0 & 0 \\
\hline 11 & 3,11 & $\begin{array}{l}\text { Belt dilengkapi dengan } \\
\text { lapisan carcas }\end{array}$ & & $\mathrm{Ya}$ \\
\hline
\end{tabular}


Dari hasil perhitungan diperoleh spesifikasi teknis belt conveyor untuk memenuhi kapasitas sebesar 150 tph untuk mengangkut cargo bag dengan massa jenis $180 \mathrm{Kg} / \mathrm{m}^{3}$ sejauh 16 m sebagai berikut:

$\begin{array}{lll}\text { Luas cross section area } & =0,0915 \mathrm{~m} \\ \text { Kecepatan belt } & =2,54 \mathrm{~m} / \mathrm{s} \\ \text { Kapasitas belt conveyor } & =150,65 \mathrm{tph} \approx 150 \mathrm{tph} \\ \text { Tarikan belt teoritis } & =22230 \mathrm{~N} \\ \text { Daya motor penggerak } & =56,47 \mathrm{~kW} \approx 60 \mathrm{~kW} \\ \text { Kecepatan rotasi motor } & =690 \mathrm{rpm}\end{array}$

\section{Penyusunan konsep produk}

Dalam membuat konsep produk mengacu pada kebutuhan pelanggan pada tahap identifikasi user dan selanjutnya setiap metrik dapat dikembangkan menjadi beberapa konsep. Dari hasil pengembangan konsep didapatkan 2 konsep "Konsep A" dan "Konsep B" yang memiliki perbedaan pada tiga metrik kebutuhan user yaitu : Desain rangka, model roda, serta bahan dari motor penggerak. Ketiga metrik ini dapat dikembangkan tanpa mengganggu sistem kerja dari belt conveyor sendiri. Dimana pada desain rangka Konsep A menggunakan desain hidraulik dan Konsep B menggunakan frame welding model, untuk model roda Konsep A menggunakan roullete wheel dan Konsep B menggunakan $V$ model wheel dan bahan cover motor Konsep A menggunakan bahan steel alloy dan Konsep B menggunakan bahan akrilik. Spesifikasi kedua konsep seperti yang tertera pada Tabel 3.

Tabel 3 Konsep belt conveyor

\begin{tabular}{|c|c|c|c|c|}
\hline No & Metrik & Satuan & Konsep A & $\begin{array}{l}\text { Konsep } \\
\text { B }\end{array}$ \\
\hline 1 & $\begin{array}{l}\text { Panjang belt conveyor } \\
16 \mathrm{~m}\end{array}$ & $m$ & 16 & 16 \\
\hline 2 & $\begin{array}{l}\text { Dilengkapi switch } \\
\text { on/off pada motor } \\
\text { penggerak }\end{array}$ & List & $\mathrm{Ya}$ & $\mathrm{Ya}$ \\
\hline 3 & Desain rangka & Jenis & Hidraulik & $\begin{array}{l}\text { Frame } \\
\text { welding }\end{array}$ \\
\hline 4 & $\begin{array}{l}\text { Belt conveyor } \\
\text { dilengkapi chip } \\
\text { cleaner dan belt } \\
\text { cleaner }\end{array}$ & Jenis & Ya & $\mathrm{Ya}$ \\
\hline 5 & $\begin{array}{l}\text { Memiliki kapasitas } \\
\text { diatas } 80 \text { tph }\end{array}$ & tph & 150 & 150 \\
\hline 6 & Model roda & $\mathrm{mm}$ & $\begin{array}{l}\text { Roulette } \\
\text { wheel }\end{array}$ & $\begin{array}{l}V \text { model } \\
\text { wheel }\end{array}$ \\
\hline 7 & $\begin{array}{l}\text { Tinggi skirt rubber } \\
\text { pada bagian kanan } \\
\text { dan kiri belt }\end{array}$ & $\mathrm{mm}$ & 250 & 250 \\
\hline 8 & $\begin{array}{l}\text { Bahan cover motor } \\
\text { penggerak }\end{array}$ & Jenis & $\begin{array}{l}\text { Steel } \\
\text { alloy }\end{array}$ & Acrylic \\
\hline 9 & $\begin{array}{l}\text { Belt conveyor tidak } \\
\text { menggunakan } \\
\text { peralatan pendukung }\end{array}$ & Unit & $\mathrm{Ya}$ & $\mathrm{Ya}$ \\
\hline 10 & Tingkat polutan & ppm & 0 & 0 \\
\hline 11 & $\begin{array}{l}\text { Belt dilengkapi } \\
\text { dengan lapisan carcas }\end{array}$ & Jenis & $\mathrm{Ya}$ & $\mathrm{Ya}$ \\
\hline
\end{tabular}

Setelah menentukan spesifikasi dari kedua konsep yang dikembangkan maka selanjutnya hasil penentuan spesifikasi dari konsep tersebut akan diinterpretasikan dalam bentuk drawing CAD. Hasil intepretasi konsep A dan B dalam bentuk desain dapat dilihat pada Gambar 2 dan 3.

\section{Pemilihan konsep produk}

Kriteria dipilih berdasarkan kebutuhan pelanggan yang telah diidentifikasikan oleh tim. Kriteria seleksi seharusnya dipilih untuk membedakan konsep-konsep, namun karena setiap kriteria diberi bobot yang sama pada penyaringan konsep, tim seharusnya tidak mencantumkan kriteria yang dianggap kurang penting agar perbedaan antara konsep-konsep dapat terlihat pada nyata pada hasil seleksi konsep (Ulrich dan Eppinger, 2011). Tabel 4 menunjukkan metrik penilaian konsep belt conveyor.

Tabel 4 Penilaian konsep belt conveyor

\begin{tabular}{|c|c|c|c|c|c|}
\hline \multirow{2}{*}{ Kriteria } & \multirow{2}{*}{$\begin{array}{l}\text { Bo- } \\
\text { bot }\end{array}$} & \multicolumn{2}{|c|}{ Konsep A } & \multicolumn{2}{|c|}{ Konsep B } \\
\hline & & $\begin{array}{l}\text { Ra- } \\
\text { ting }\end{array}$ & $\begin{array}{c}\text { Nilai } \\
\text { Bobot }\end{array}$ & $\begin{array}{l}\mathrm{Ra}- \\
\text { ting }\end{array}$ & $\begin{array}{l}\text { Nilai } \\
\text { Bobot }\end{array}$ \\
\hline $\begin{array}{l}\text { Digunakan untuk } \\
\text { mengangkut } \\
\text { material } \\
\text { bermassa berat }\end{array}$ & $20 \%$ & 3 & 0,60 & 3 & 0,60 \\
\hline $\begin{array}{l}\text { Peralatan semi- } \\
\text { otomatis }\end{array}$ & $5 \%$ & 3 & 0,15 & 3 & 0,15 \\
\hline $\begin{array}{l}\text { Motor dilengkapi } \\
\text { switch }\end{array}$ & $5 \%$ & 3 & 0,15 & 3 & 0,15 \\
\hline $\begin{array}{l}\text { Dilengkapi aksesori } \\
\text { pembersih }\end{array}$ & $10 \%$ & 3 & 0,30 & 3 & 0,30 \\
\hline Kekuatan belt & $15 \%$ & 3 & 0,45 & 3 & 0,45 \\
\hline Kekuatan frame & $15 \%$ & 3 & 0,45 & 2 & 0,30 \\
\hline Kekuatan roda & $15 \%$ & 3 & 0,45 & 2 & 0,30 \\
\hline Desain baru & $5 \%$ & 3 & 0,15 & 1 & 0,05 \\
\hline Tampilan & $5 \%$ & 3 & 0,15 & 4 & 0,20 \\
\hline $\begin{array}{l}\text { Mobilitas } \\
\text { penggunaan }\end{array}$ & $5 \%$ & 3 & 0,15 & 3 & 0,15 \\
\hline Total Nilai & & & & & 2,65 \\
\hline Peringkat & & & 1 & & 2 \\
\hline Lanjutkan & & & $\mathrm{a}$ & & idak \\
\hline
\end{tabular}

\section{Desain belt conveyor terpilih}

Berdasarkan hasil pengolahan data maka konsep desain belt conveyor yang dipilih adalah konsep A, dimana hasil rancangan belt conveyor ini memiliki spesifikasi panjang sabuk mencapai $16 \mathrm{~m}$, dilengkapi dengan switch yang builtin pada motor, desain rangka hidraulik, dilengkapi aksesori pembersih, kapasitas mencapai $150 \mathrm{tph}$, desain roda roulette wheel, tinggi skirts rubber $250 \mathrm{~mm}$, bahan cover motor adalah steel alloy, dan belt menggunakan lapisan carcas sebagai penguat belt. 


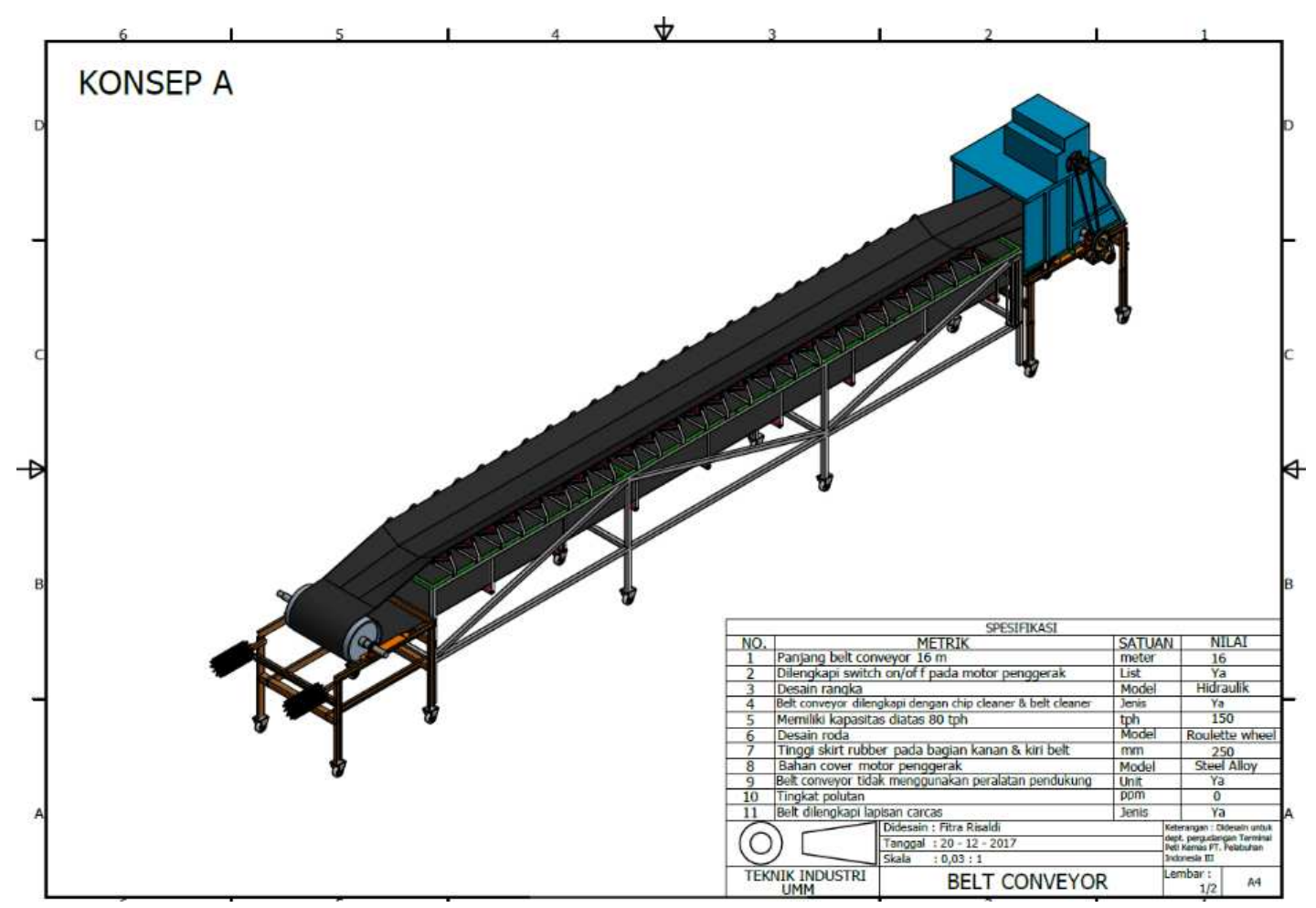

Gambar 2 Rancangan belt conveyor konsep A

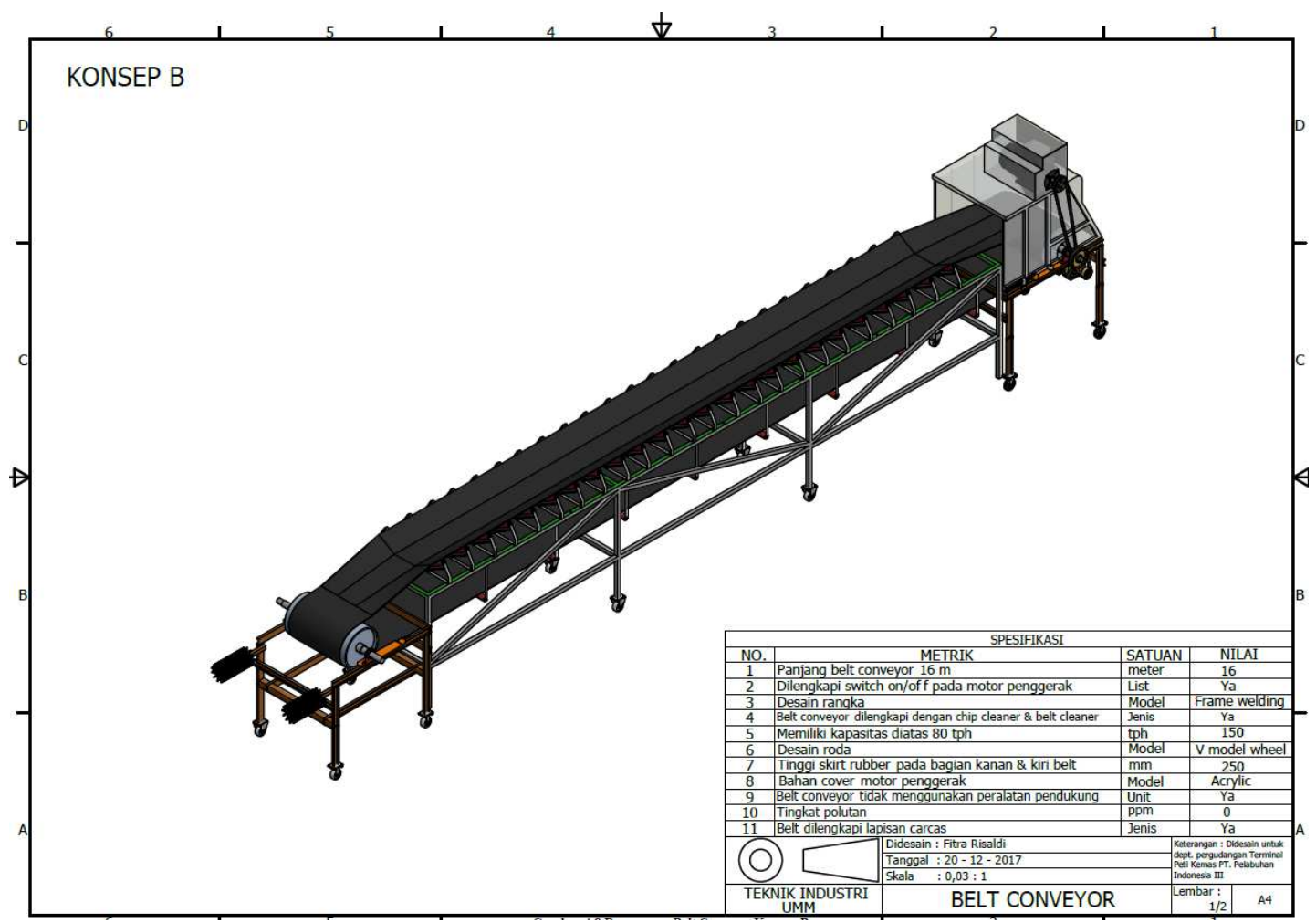

Gambar 3 Rancangan belt conveyor konsep B

Hasil rancangan belt conveyor yang terpilih dapat dilihat pada Gambar 4 dan 5. Gambar 4 menunjukkan hasil rancangan belt conveyor yang dipilih serta daftar komponen penyusunnya dan kuantitas dari setiap komponen. Gambar 5 menjelaskan hasil rancangan dalam bentuk gambar urai disertai nama dari setiap komponen penyusunnya. Tabel 5 menunjukkan perbandingan penggunaan material handling equipment kondisi eksisting dengan usulan rancangan. 
Tabel 5 Analisa kondisi eksisting dengan usulan rancangan

\begin{tabular}{|c|c|c|}
\hline Atribut & Kondisi eksisting & Usulan rancangan \\
\hline $\begin{array}{l}\text { Jenis material } \\
\text { handling } \\
\text { equipment }\end{array}$ & Forklift & Belt conveyor \\
\hline Kapasitas angkut & 80 & 150 \\
\hline $\begin{array}{l}\text { Peralatan } \\
\text { pendukung }\end{array}$ & pallet & - \\
\hline Tenaga kerja & $\begin{array}{l}\text { Operator forklift } \\
\text { dan buruh angkut }\end{array}$ & Buruh angkut \\
\hline Daya penggerak & Solar & Listrik \\
\hline Harga unit MHE & $\mathrm{Rp} 712.000 .000$ & $\operatorname{Rp} 674.092 .500$ \\
\hline Sistem operasi & $\begin{array}{l}\text { Pengambilan pallet } \\
\text { - penurunan } \\
\text { material dari } \\
\text { tumpukan - } \\
\text { penyusunan } \\
\text { material ke pallet - } \\
\text { pengangkutan - } \\
\text { penyusunan } \\
\text { material ke truk }\end{array}$ & $\begin{array}{l}\text { Penurunan } \\
\text { material dari } \\
\text { tumpukan - } \\
\text { pengangkutan - } \\
\text { penyusunan } \\
\text { material ke truk }\end{array}$ \\
\hline
\end{tabular}

\section{Kesimpulan}

Belt conveyor dirancang berdasarkan kebutuhan user. Spesifikasi yang dimiliki yaitu panjang sabuk mencapai
$16 \mathrm{~m}$, dilengkapi dengan switch yang built-in pada motor, desain rangka hidraulik, dilengkapi aksesori pembersih, kapasitas mencapai $150 \mathrm{tph}$, desain roda roulette wheel, tinggi skirts rubber $250 \mathrm{~mm}$, bahan cover motor adalah steel alloy, dan belt menggunakan lapisan carcas sebagai penguat belt. Berdasarkan kapasitas angkutnya, penggunaan belt conveyor pada proses bongkar muat mampu meningkatkan kapasitas dari 80 tph menjadi 150 tph untuk mengangkut barang tipe cargo bag dengan berat maksimal $180 \mathrm{~kg} / \mathrm{m}^{3}$.

\section{Referensi}

Cahyadi, D., Azis, G.F (2015). Perancangan belt conveyor kapasitas 30 ton/jam untuk alat angkut beras. Jurnal Sintek, Vol. 9, No. 1, 13-17.

Ulrich K.T., Eppinger S.D. (2011) Product design and development. McGraw-Hill Education.

Zainuri M. (2006) Mesin Pemindah bahan (material handling equipment). Penerbit Andi.

Aosoby, R., Rusiato, T., Waluyo J. (2016) Perancangan belt conveyor sebagai pengangkut batubara dengan kapasitas 2700 ton/jam, Jurnal Teknik Mesin, Vol.3, No. 1, 45-51.

Raharjo, R (2013) Rancang bangun belt conveyor trainer sebagai alat bantu pembelajaran, Jurnal Teknik Mesin Politeknik Kediri, , Vol 4, No. 2, 15-26.

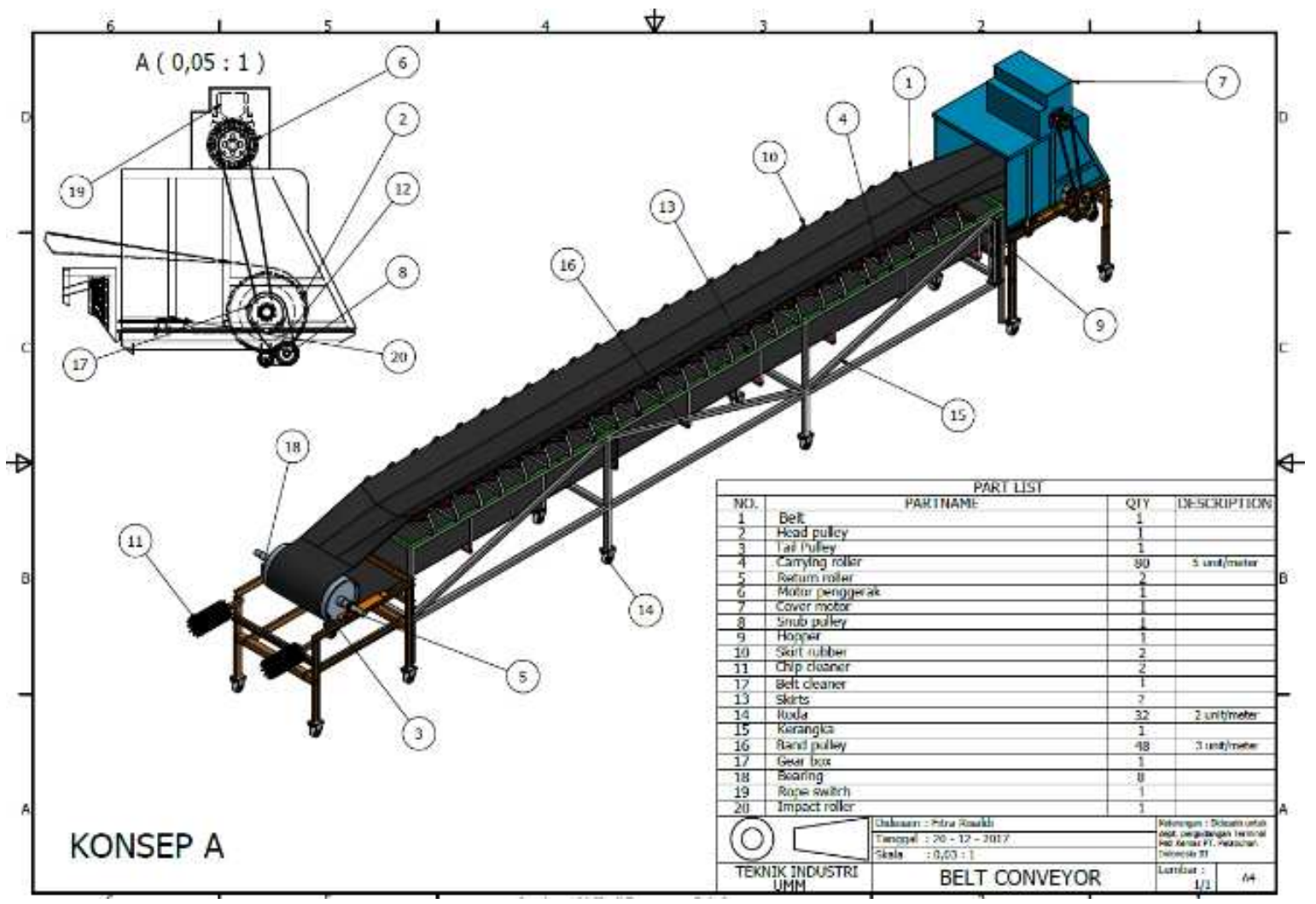

Gambar 4 Rancangan belt conveyor terpilih 


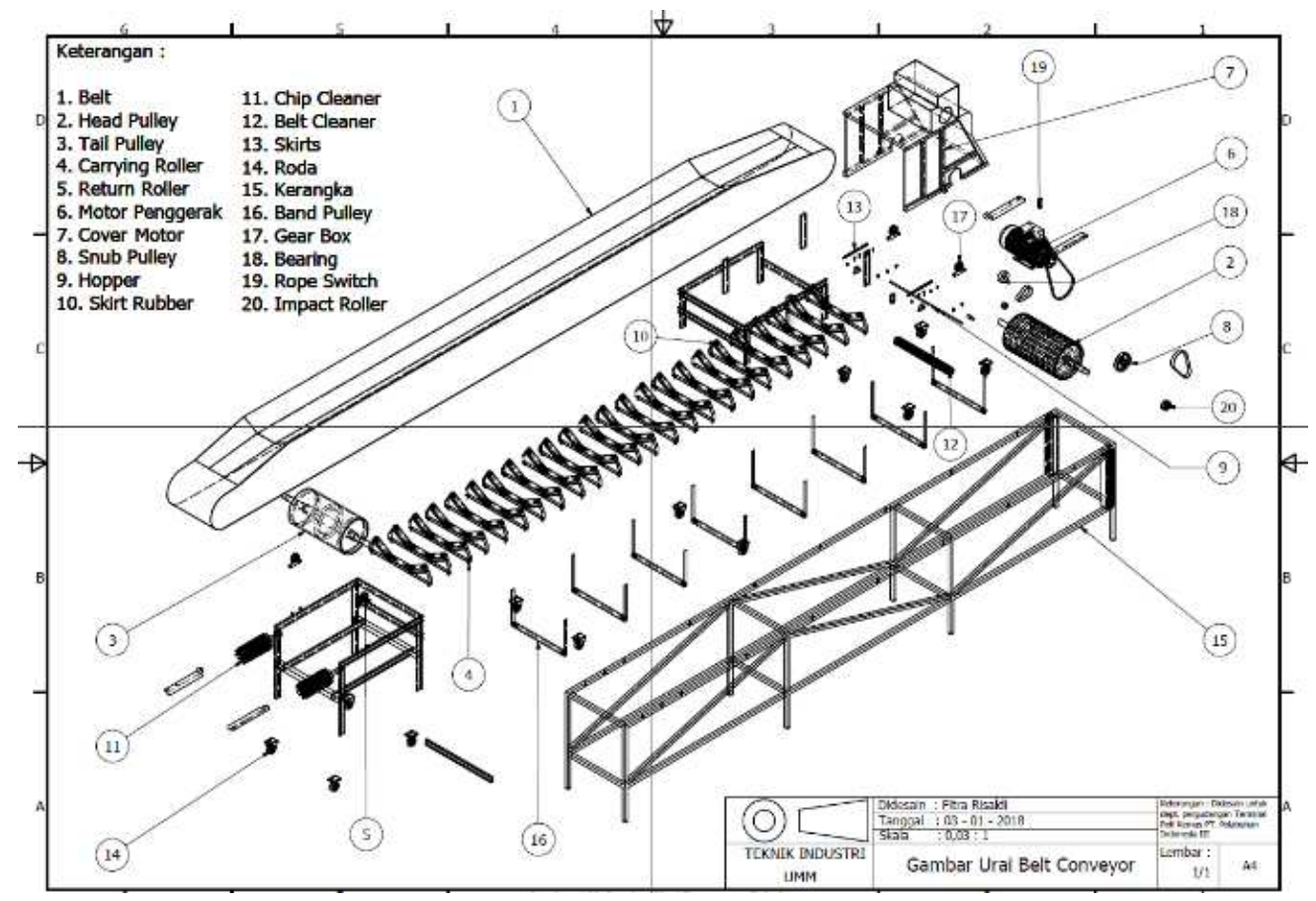

Gambar 5. Gambar urai belt conveyor terpilih 